\title{
Treatment and survival of osteosarcoma and Ewing sarcoma of the skull: a SEER database analysis
}

\author{
Enrico Martin $^{1,2}$ - Joeky T. Senders ${ }^{1,3} \cdot$ P. Valerie ter Wengel ${ }^{4,5} \cdot$ Timothy R. Smith $^{1}$ - Marike L. D. Broekman ${ }^{1,6,7}$
}

Received: 26 September 2018 / Accepted: 26 November 2018 / Published online: 21 December 2018

(C) The Author(s) 2018

\begin{abstract}
Background Common primary bone tumors include osteosarcomas (OSC) and Ewing sarcomas (EWS). The skull is a rare site, and literature about their treatment and survival is scarce. Using the Surveillance, Epidemiology, and End Results (SEER) database, this study aims to assess the treatment and survival of skull OSC and skull EWS, as well as predictors for survival. Methods Skull OSC and EWS cases were obtained from the SEER database. Patient and tumor characteristics, treatment modalities, and survival were extracted. Overall survival (OS) was assessed using multivariable Cox proportional hazard regression stratified by tumor histology. Kaplan-Meier curves were constructed for OS comparing OSC and EWS, as well as histological subtypes in OSC.

Results A total of 321 skull OSC and 80 skull EWS patients were registered from 1973 to 2013. EWS was more common in younger patients $(p<0.001)$. Resection was the predominant treatment strategy $(80.1 \%)$, frequently in combination with adjuvant radiotherapy (30.4\%). The 5-year survival rate varied significantly between OSC and EWS (51.0\% versus 68.5\%, $p=0.02)$. Kaplan-Meier curves show that EWS had a significantly better survival compared to OSC. Comparing histological subtypes of skull OSC, chondroblastic OSC had the best OS, Paget OSC the worst. Older age, tumor advancement, no surgical treatment, and the use of radiotherapy were identified as independent predictors of decreased OS in skull OSC.

Conclusion Overall prognosis is better for EWS compared to OSC. Chondroblastic OSC have the best overall survival, while OSC associated with Paget's disease of the bone has the poorest overall survival.
\end{abstract}

Keywords Ewing sarcoma $\cdot$ Osteosarcoma $\cdot$ Cranial $\cdot$ Skull tumor $\cdot$ SEER

This article is part of the Topical Collection on Tumor - Other

Marike L. D. Broekman

m.l.d.broekman@lumc.nl

1 Computational Neurosciences Outcomes Center, Department of Neurosurgery, Brigham and Women's Hospital, Harvard Medical School, 60 Fenwood Road, Boston, MA 02115, USA

2 Department of Plastic and Reconstructive Surgery, University Medical Center Utrecht, Utrecht, The Netherlands

3 Department of Neurosurgery, Brain Center Rudolf Magnus, University Medical Center Utrecht, Utrecht, The Netherlands

4 Department of Neurosurgery, Slotervaart Ziekenhuis Amsterdam, Amsterdam, The Netherlands

5 Department of Neurosurgery, VU Medical Center Amsterdam, Amsterdam, The Netherlands

6 Department of Neurosurgery, Leiden University Medical Center, PO Box 9600, 2300 RC Leiden, The Netherlands

7 Department of Neurosurgery, Haaglanden Medical Center, The Hague, The Netherlands

\section{Introduction}

Primary malignant bone tumors of the skull are rare entities. Osteosarcomas (OSC) and Ewing sarcomas (EWS) are common primary bone tumors which can also affect the skull. However, in comparison to skull base chordoma and chondrosarcoma, they are rare entities. OSC are the most common malignant tumors of the bone, with a peak incidence in adolescence during the growth spurt [27]. They can arise after radiotherapy, in Paget's disease of the bone, but also in several hereditary diseases $[6,27]$. As in other sites of origin, skull OSC can also arise after trauma $[23,29]$. It is estimated that $1.6 \%$ of all OSC are present in the skull [28]. EWS are the second most common primary bone malignancies in children specifically [45]. They typically occur in children and adolescents, but also in adults [27, 45]. The reported incidence of primary cranial EWS is approximately $1 \%$ of all possible sites of origin $[2,16,44]$. 
To date, literature on OSC and EWS primarily arising from the skull has been limited to case reports or small case series $[14,22,23,39,40]$. This is primarily due to the low frequency of this tumor site. Consequently, survival and ideal treatment of these rare tumors is not very well known. Moreover, studies have, yet, neither been able to investigate possible predictors of worse survival, nor been able to stratify results for histological subtypes of skull OSC. The Surveillance, Epidemiology, and End Results (SEER) program is a cancer registry that collects data from 18 geographic areas across the USA, currently encompassing approximately $28 \%$ of its population [34]. It provides a means of assessing possible predictive factors of survival and treatment strategies for rare tumors such as primary osseous malignancies of the skull. This study aims to evaluate the treatment and survival of skull OSC and skull EWS as well as determinants for decreased survival. Also, skull OSC will be stratified by histological subtype to investigate possible differences in survival.

\section{Methods}

\section{Data source}

Data were obtained from the SEER program from 1973 to 2013. The International Classification of Disease for Oncology (ICD-O-3) histology codes were used to identify cases. OSC (ICD-O-3: 9180/3, 9181/3, 9182/3, 9183/3, 9184/3, 9185/3, 9186/3, 9193/3), and EWS (9260/3) arising from the skull or intracranially were selected (C41.0, C70.0, C71.1, C71.2). Over time, ICD-codes have been updated according to new classifications by trained clinical reviewers. Parosteal osteosarcomas are low-grade tumors and were therefore not included in our analysis. Our Institutional Review Board has exempted the SEER program from review.

\section{Covariates}

Covariates extracted for analysis were as follows: sex, age, or categorical age ( $\leq 18,19-50$, and $\geq 50$ years), race (White, Black, Asian, and other), period of diagnosis (1973-1983, 1984-1993, 1994-2003, 2004-2013), tumor size, extent of surgery (no surgery, partial resection, gross total resection, surgery NOS, unknown status of surgery), radiotherapy (yes/ no), and timing of radiotherapy to surgery (prior to, after, during, prior to, and after surgery). Extent of disease (EOD) was reclassified into one variable, as previously established in the literature, using both EOD and collaborative stage (CS) coding methods, into local, locally advanced, and metastatic [35]. Surgical procedures were coded differently in SEER over time. In order to evaluate surgery from all time periods, a single variable was constructed: no surgery $(<1998$ codes: 00, 01; for 1998+: 00), partial resection (<1998: 02, 10, 20,
28; $1998+: 15,19,25,26)$, gross total resection (GTR, < 1998: 30, 38, 40, 48; $1998+: 30,40,41,42,55)$, surgery not otherwise specified (<1998: 60, 68, 90; $1998+: 90)$, and unknown status of surgery $(<1998$ : 09, 80).

\section{Statistical analysis}

Baseline characteristics of OSC and EWS were analyzed using descriptive statistics. Only primary tumors were included in the survival analyses. Multivariable Cox proportional hazard analyses were performed stratified for OSC and EWS to evaluate possible independent predictors of overall survival (OS). Variables of interest were identified through univariable analysis and included in multivariable analysis when $p$ values were $<0.20$ [7]. The rule of one predictor per 10 events was used to avoid overfitting of the model. $p$ values $<0.05$ were considered statistically significant. Missing values were imputed using a validated random forest algorithm from the MICE package in $\mathrm{R}$, which has been shown to yield the highest reliability for data imputation [47, 48]. Schoenfeld residuals were assessed to check if variables were independent from time. All variables included in the final models had a $p$ value $>0.05$. Global $p$ values of the osteosarcoma model and Ewing sarcoma model were 0.12 and 0.33 respectively. Kaplan-Meier curves for OS were constructed for EWS and OSC. Subsequent analyses were performed for skull OSC subtypes with 10 or more registered; remaining tumors were grouped into the "other" group. Statistical analyses and figures were conducted using $\mathrm{R}$ version 3.3.3 (R Core Team 2016).

\section{Results}

\section{Patient population}

A total of 401 patients were identified in the SEER database: 321 patients with skull osteosarcomas (OSC) (80.0\%) and 80 patients with skull Ewing sarcomas (EWS) (20.0\%, Table 1). The median age was 32 years (IQR 17-52) overall, but 16 years (IQR 8-29) in EWS and 38 years (IQR 21-57) in OSC ( $p<0.001$, Fig. 1). A slight majority of all patients was male $(52.4 \%)$, and most commonly White $(81.5 \%)$, without significant differences between EWS and OSC. Most tumors were locoregional $(57.9 \%)$ and metastases were infrequent at time of diagnosis: $4.7 \%$ and $2.5 \%$ for OSC and EWS respectively $(p>0.05)$. There were no differences in tumor size and median tumor size was $45.0 \mathrm{~mm}$ (IQR 28.0-51.0). EWS had statistically significant different 5-year survival rates compared OSC; $68.5 \%$ and $51.5 \%$ respectively $(p=0.02)$. 
Table 1 Patient and treatment demographics in skull osteosarcomas and Ewing sarcomas

\begin{tabular}{|c|c|c|c|c|c|}
\hline Characteristic & Definition & Total $(N=401)$ & Osteosarcoma $(N=321)$ & Ewing Sarcoma $(N=80)$ & $P$ \\
\hline \multirow[t]{5}{*}{ Age } & $\leq 18$ & $111(27.7)$ & $64(19.9)$ & $47(58.8)$ & \multirow[t]{3}{*}{$<0.001$} \\
\hline & $19-50$ & $181(45.1)$ & $153(47.7)$ & $28(35.0)$ & \\
\hline & $50+$ & $109(27.2)$ & $104(32.4)$ & $5(6.3)$ & \\
\hline & Median (year) & 32 & 38 & 16 & \multirow[t]{2}{*}{$<0.001$} \\
\hline & $\mathrm{IQR}$ & $17-52$ & $21-57$ & $8-29$ & \\
\hline \multirow[t]{2}{*}{ Sex } & Female & $191(47.6)$ & $152(47.2)$ & $40(50.0)$ & \multirow[t]{2}{*}{0.64} \\
\hline & Male & $210(52.4)$ & $170(52.8)$ & $40(50.0)$ & \\
\hline \multirow[t]{4}{*}{ Race } & White & $327(81.5)$ & $257(80.1)$ & $70(87.5)$ & \multirow[t]{4}{*}{0.30} \\
\hline & Black & $48(12.0)$ & $43(13.4)$ & $5(6.3)$ & \\
\hline & Asian and other & $24(6.0)$ & $19(5.9)$ & $5(6.3)$ & \\
\hline & Unknown & $2(0.5)$ & $2(0.6)$ & $0(0.0)$ & \\
\hline \multirow[t]{4}{*}{ Extent of disease } & Local & $105(26.2)$ & $86(26.8)$ & $19(26.2)$ & \multirow[t]{4}{*}{0.72} \\
\hline & Locoregional & $232(57.9)$ & $182(56.7)$ & $50(62.5)$ & \\
\hline & Metastasized & $17(4.2)$ & $15(4.7)$ & $2(2.5)$ & \\
\hline & Unknown & 47 (11.7) & $38(11.8)$ & $9(11.3)$ & \\
\hline \multirow[t]{5}{*}{ Tumor size } & $\leq 50 \mathrm{~mm}$ & $179(44.6)$ & $145(45.2)$ & $34(42.5)$ & \multirow[t]{3}{*}{0.78} \\
\hline & $>50 \mathrm{~mm}$ & $103(25.7)$ & $80(24.9)$ & $23(28.8)$ & \\
\hline & Missing & $119(29.7)$ & $96(29.9)$ & $23(29.7)$ & \\
\hline & Median (mm) & 45.0 & 45.0 & 50.0 & \multirow[t]{2}{*}{0.53} \\
\hline & $\mathrm{IQR}(\mathrm{mm})$ & $35.0-60.0$ & $35.0-60.0$ & $40.0-60.0$ & \\
\hline \multirow[t]{5}{*}{ Treatment modality } & Sx only & $192(47.9)$ & $177(55.1)$ & $15(18.8)$ & \multirow[t]{5}{*}{$<0.001$} \\
\hline & Rx only & $24(6.0)$ & $9(2.8)$ & $15(18.8)$ & \\
\hline & Sx and $\mathrm{Rx}$ & $129(32.2)$ & $85(26.5)$ & $44(55.0)$ & \\
\hline & None & $33(8.2)$ & $30(9.3)$ & $3(3.8)$ & \\
\hline & Unknown & $23(5.7)$ & $20(6.2)$ & $3(3.8)$ & \\
\hline \multirow[t]{5}{*}{ Extent of resection } & No surgery & $57(14.2)$ & $39(12.1)$ & $18(22.5)$ & \multirow[t]{5}{*}{0.12} \\
\hline & Partial resection & $138(34.4)$ & $109(34.0)$ & $29(36.3)$ & \\
\hline & GTR & $121(30.2)$ & $101(31.5)$ & $20(25.0)$ & \\
\hline & Surgery NOS & $71(17.7)$ & $61(19.0)$ & $10(12.5)$ & \\
\hline & Unknown & $14(3.5)$ & $11(3.4)$ & $3(3.8)$ & \\
\hline \multirow[t]{3}{*}{ Radiotherapy } & No radiation & $231(57.6)$ & $212(66.0)$ & $19(23.8)$ & \multirow[t]{3}{*}{$<0.001$} \\
\hline & Any form radiation & $163(40.1)$ & $100(31.2)$ & $61(76.3)$ & \\
\hline & Unknown & $9(2.2)$ & $9(2.8)$ & $0(0.0)$ & \\
\hline \multirow[t]{5}{*}{ Radiotherapy sequence } & No $\mathrm{Rx}$ or no $\mathrm{Sx}$ & $271(N A)$ & $235(N A)$ & $36(N A)$ & \multirow[t]{5}{*}{$<0.001$} \\
\hline & $\mathrm{Rx}$ after $\mathrm{Sx}$ & $122(93.8)$ & $79(91.9)$ & $43(97.7)$ & \\
\hline & Rx before $\mathrm{Sx}$ & $6(4.6)$ & $5(5.8)$ & $1(2.3)$ & \\
\hline & $\mathrm{Rx} b / \mathrm{a} \mathrm{Sx}$ & $0(0.0)$ & $0(0.0)$ & $0(0.0)$ & \\
\hline & Intraoperative $\mathrm{Rx}$ & $2(1.5)$ & $2(2.3)$ & $0(0.0)$ & \\
\hline \multirow[t]{4}{*}{ Time period } & $1973-1983$ & $37(9.2)$ & $29(9.0)$ & $8(10.0)$ & \multirow[t]{4}{*}{0.001} \\
\hline & 1984-1993 & $49(12.2)$ & $46(14.3)$ & $3(3.8)$ & \\
\hline & $1994-2003$ & $138(34.4)$ & $119(37.1)$ & $19(23.8)$ & \\
\hline & 2004-2013 & $177(44.1)$ & $127(39.6)$ & $50(62.5)$ & \\
\hline 5-Y survival* & $\%$ & $54.5 \%$ & $51.0 \%$ & $68.5 \%$ & 0.02 \\
\hline $10-\mathrm{Y}$ survival ${ }^{* *}$ & $\%$ & $37.4 \%$ & $36.1 \%$ & $44.4 \%$ & 0.34 \\
\hline
\end{tabular}

They are all significant at a $p$-value smaller than 0.05

*210 OS, 54 EWS eligible

**183 OS, 36 EWS eligible

$b / a$ before and after, IQR interquartile range, GTR gross total resection, $m m$ millimeters, NOS not otherwise specified, $S x$ surgery, $R x$ radiotherapy, $Y$ year 


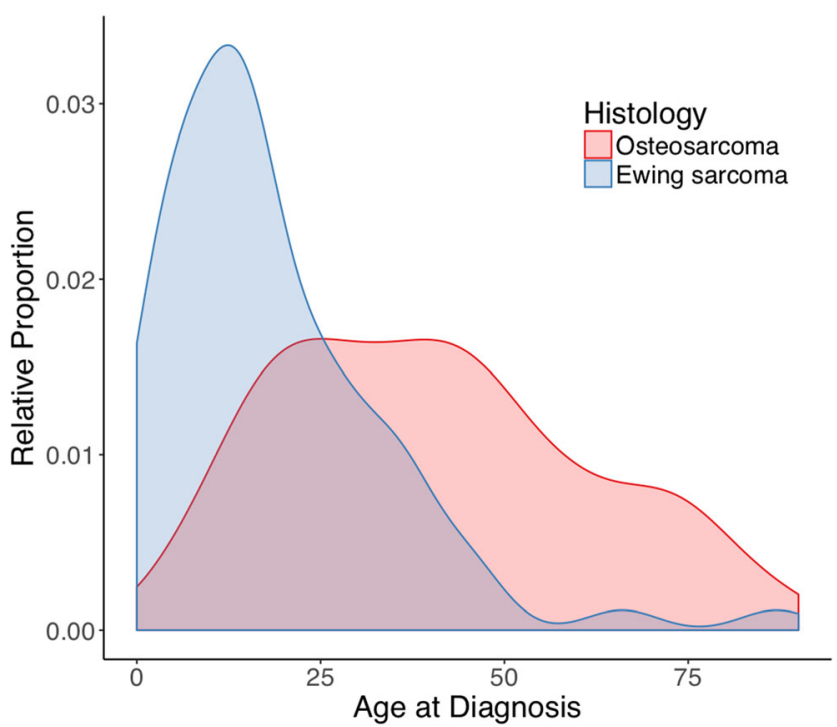

Fig. 1 Relative age distribution of osteosarcoma and Ewing sarcoma of the skull

\section{Treatment modalities}

Most patients were only treated surgically (47.9\%), with a combination of surgery and radiotherapy being the second most common treatment modality (32.2\%, Table 1). Radiotherapy was more commonly administered in EWS, but in most cases also in combination with surgery. Both in EWS and in OSC, radiation was most commonly administered postoperatively ( $97.7 \%$ and $91.9 \%$ respectively). Extent of resection did not differ significantly between both tumors $(p=0.12)$. Partial resection was achieved in $41.8 \%$ and GTR in $36.7 \%$ of all cases.

\section{Overall survival in EWS and OSC}

EWS have a significantly better survival compared to OSC (Fig. 2a). In skull OSC, older age ( $\geq 50$ years), no surgical treatment, advancement of disease, and early cases (19731983) were independent predictors of decreased overall survival after correction for sex and tumor size (Fig. 3). Patients that did not receive radiotherapy were independently correlated with superior OS. In skull EWS, no factors were identified that significantly affected OS in multivariate analyses (Fig. 4).

\section{Differences between osteosarcoma subtypes}

There are several subtypes of OSC: osteoblastic, chondroblastic, fibroblastic, telangiectatic, small cell, lowgrade central, parosteal, periosteal, high grade surface, and secondary including those arising in Paget's disease of the bone [31]. The SEER database included 4 subtypes of skull OSC with more than 10 cases. These are 66 chondroblastic OSC, 14 fibroblastic OSC, 11 Paget OSC, and 222 OSC not otherwise specified. While most OSC arose in patients aged 19-50, those arising as a result of Paget's disease were all in patients over 50 years (Table 2). Sex, treatment modalities, extent of disease, and tumor size did not differ significantly between these subtypes. However, 5- and 10-year survival rates significantly varied between the subtypes $(p<0.001)$. Kaplan-Meier curves showed that chondroblastic OSC have the best overall survival, while Paget osteosarcomas had a dismal prognosis (Fig. 2b). Overall differences were statistically significant $(p<0.001)$.

\section{Discussion}

Skull OSC and EWS are rare tumor entities. Using the SEER database we identified 321 skull OSC and 80 skull EWS cases and were able to show that the latter have a significantly better overall survival. Older age, tumor advancement, no surgical treatment, the use of radiotherapy, and early cases were independent predictors of poor survival in skull OSC. As in other tumor sites, skull EWS generally occurs at a younger age and osteosarcomas have a peak incidence around 20 years of age. Both tumors were generally resected, but radiotherapy is more commonly administered in EWS. In subtypes of OSC, chondroblastic OSC had a significantly better overall survival compared to osteoblastic OSC, while those arising in Paget's disease of the bone have the most dismal prognosis.

\section{Osteosarcomas of the skull}

Since its first description by Garland in 1945, literature has been filled with a little more than 150 skull OSC cases to date $[18,23]$. An estimated $1.6 \%$ of all OSC arises from the skull [28]. They frequently present as a painless or only mildly tender lesion, while those arising in long bones are typically painful $[23,26,40]$. Other symptoms are dependent on their anatomical site [40]. They can include headache, cranial nerve palsy, exophthalmos, and visual impairment [17, 36]. Intracranial involvement has been reported in $14.1 \%$ of all skull OSC [42]. These cases all had dismal prognoses with less than $30 \%$ surviving more than 1 year [42].

If a bone sarcoma of the skull is suspected, infiltrative lesion identified on plain radiograph should be followed by an MRI to further characterize the tumor location, extension, and aspect [37]. Preferably, a core needle biopsy or open biopsy is performed [37]. If an OSC is diagnosed, patients should receive neoadjuvant chemotherapy, followed by resection of detectable disease and adjuvant chemotherapy [4, 15, 23, 37, 40, 42]. Currently, the combination of methotrexate, Adriamycin, and cisplatin has become standard of care [15, 37]. Radiotherapy may also be administered, but since OSC is relatively radiation-resistant, this may more commonly be reserved for inoperable or more advanced cases [40, 41]. The 
Fig. 2 a Kaplan-Meier curves showing cumulative overall survival of osteosarcoma and Ewing sarcoma patients. b Kaplan-Meier curves showing cumulative overall survival in histological subtypes of osteosarcoma patients
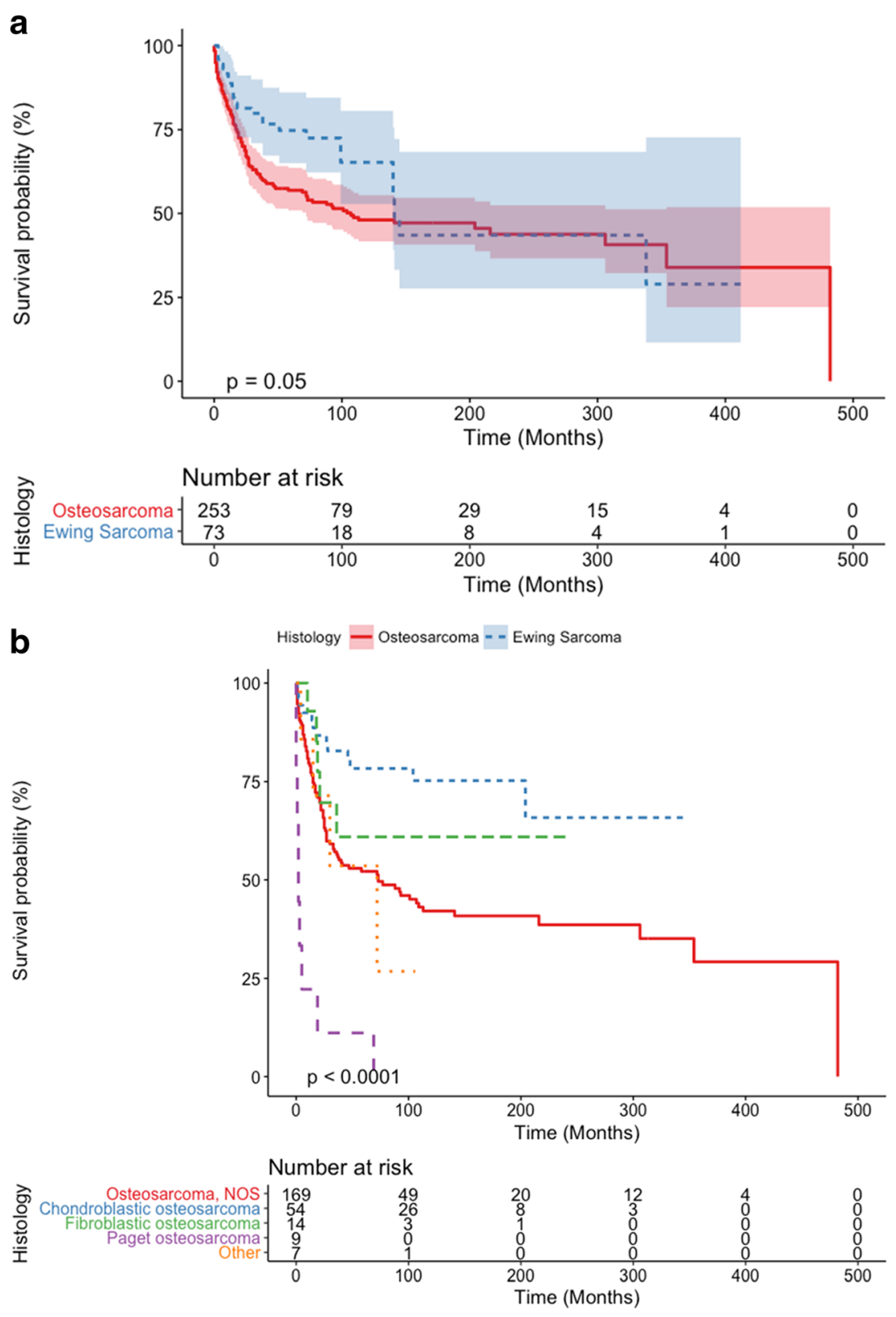

Histology — Osteosarcoma, NOS - - Chondroblastic osteosarcoma - Fibroblastic osteosarcoma - Paget osteosarcoma * Other

latter may partially explain the association of radiotherapy and overall survival in this study; however, only its association has been studied in this study. The effect of radiotherapy after resections with positive margins still remains to be investigated $[21,23]$. Dural involvement is not uncommon and in cases with dural involvement, the dura needs to be resected [23, 29, 50]. Although wide surgical margins seem to improve survival $[17,36]$, this is commonly difficult to achieve because of adjacent critical structures $[22,50]$. This study also showed a $31.5 \%$ GTR rate. Chemotherapy may improve outcomes by decreasing preoperative tumor size which might improve resection margins or management of residual tumor when GTR is not achievable [43].
This study found that Paget OSC has a significantly worse prognosis compared to osteoblastic OSC. In other sites of OSC, Paget-associated OSC also tend to occur in older people and have a more dismal prognosis $[3,24,25]$. The worse survival rate may partially be due to age, but stromal elements have also been shown to play a role in the malignant degeneration of bone, likely resulting in more aggressive disease [25]. The skull seems to be a preferential site for Paget OSC $[36,40]$. While this study finds a 5-year survival rate of $51.0 \%$, others reported $10-31.6 \%[9,11,42]$. However, these often include early cases before the chemotherapy era. Metastasis of skull OSC is uncommon and less frequent compared to extracranial sites [22, 42]. Metastasis may occur to 
Fig. 3 Multivariable Cox proportional hazard model for overall survival in osteosarcoma of the skull showing hazard ratios in a forest plot with $95 \%$ confidence intervals

\begin{tabular}{|c|c|c|c|c|c|}
\hline Variable & & $\mathrm{N}$ & Hazard ratio & & p \\
\hline \multirow[t]{3}{*}{ Age Categorized } & $<19$ & 41 & $\dot{\varphi}$ & Reference & \\
\hline & $19-50$ & 137 & $\mapsto=$ & $1.45(0.75,2.80)$ & 0.269 \\
\hline & $50+$ & 75 & $\longmapsto$ & $3.42(1.75,6.69)$ & $<0.001$ \\
\hline \multirow[t]{2}{*}{ Sex } & Female & 121 & 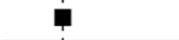 & Reference & \\
\hline & Male & 132 & - & $1.37(0.94,1.99)$ & 0.100 \\
\hline \multirow[t]{2}{*}{ Surgery } & Surgery & 221 & 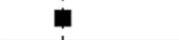 & Reference & \\
\hline & No surgery & 32 & $\mapsto$ & $3.54(2.18,5.74)$ & $<0.001$ \\
\hline \multirow[t]{2}{*}{ Radiation } & Any form of radiation & 86 & 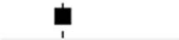 & Reference & \\
\hline & No radiation & 167 & 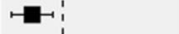 & $0.58(0.40,0.84)$ & 0.004 \\
\hline \multirow[t]{3}{*}{ Extent of disease } & Local disease & 80 & $\dot{1}$ & Reference & \\
\hline & Locally advanced & 160 & & $1.82(1.15,2.89)$ & 0.011 \\
\hline & Metastasis & 13 & $\square$ & $2.24(1.00,5.01)$ & 0.050 \\
\hline \multirow[t]{4}{*}{ Year of Diagnosis } & 2004-2013 & 103 & $\varphi$ & Reference & \\
\hline & $1973-1983$ & 22 & 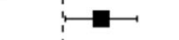 & $1.98(1.05,3.75)$ & 0.036 \\
\hline & $1984-1993$ & 34 & - & $1.24(0.70,2.20)$ & 0.453 \\
\hline & 1994-2003 & 94 & $\rightarrow$ & $1.17(0.75,1.82)$ & 0.489 \\
\hline \multirow[t]{2}{*}{ Tumor Size } & $<50 \mathrm{~mm}$ & 161 & 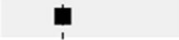 & Reference & \\
\hline & $>50 \mathrm{~mm}$ & 92 & + & $1.12(0.78,1.62)$ & 0.535 \\
\hline
\end{tabular}

the lungs or brain; similar locations compared to extracranial OSC $[8,10,42,46]$. In case of metastasis, survival is very poor $[4,26]$. Recurrence is however more common, probably due to difficulty in achieving radical margins, especially in the skull base $[10,22,23]$. Recurrence is a poor prognosticator, commonly followed by death $[10,22]$.

\section{Ewing sarcomas of the skull}

Since EWS arise in the skull in approximately only $1 \%$ of all cases, literature has been limited to case reports and case series. These EWS will most commonly present themselves with headaches and increased intracranial pressure, but scalp swelling can also be present [14, 39]. While typically EWS has an onion peel appearance, this is not always true in skull EWS $[13,39]$. As in other sites of EWS, this study shows that skull EWS presents itself typically before 20 years of age [14,
20, 27, 39]. Metastatic disease at presentation is not common, with reports varying between 0 and $30 \%$ in series including all head and neck sites [19, 39]. This is in line with the low frequency in this study.

Standard-of-care in patients with Ewing sarcoma is neoadjuvant chemotherapy followed by local control with radiotherapy or wide excision of remaining tumor within reasonable limits of safety, or a combination [14, 19, 37, 39]. After local treatment, additional chemotherapy is administered to complete a total of 14 cycles [37]. In Europe vincristine, ifosfamide, doxorubicin, and etoposide are standard regimens; while in North America, a combination of vincristine, doxorubicin, cyclophosphamide, ifosfamide, and etoposide is administered [37]. In other series, radiotherapy is often administered, ranging from 54 to $100 \%$ in case series [14, 19, 30, 39]. This is also true for this series, where surgical treatment is frequent, commonly accompanied by radiotherapy. Some
Fig. 4 Multivariable Cox proportional hazard model for overall survival in Ewing sarcoma of the skull showing hazard ratios in a forest plot with $95 \%$ confidence intervals

\begin{tabular}{|c|c|c|c|c|c|}
\hline Variable & & $\mathbf{N}$ & Hazard ratio & & $\mathbf{p}$ \\
\hline \multirow[t]{2}{*}{ Sex } & Female & 35 & a & Reference & \\
\hline & Male & 38 & - & $2.07(0.86,4.94)$ & 0.1 \\
\hline \multirow[t]{2}{*}{ Extent of Disease } & Local & 15 & & Reference & \\
\hline & Locally advanced/Metastasis & 58 & $\longrightarrow$ & $1.07(0.37,3.05)$ & 0.9 \\
\hline \multirow[t]{2}{*}{ Tumor Size } & $<50 \mathrm{~mm}$ & 48 & $\varphi$ & Reference & \\
\hline & $>50 \mathrm{~mm}$ & 25 & $\longmapsto$ & $1.20(0.52,2.76)$ & 0.7 \\
\hline
\end{tabular}


Table 2 Demographic differences per subtype of osteosarcoma

\begin{tabular}{|c|c|c|c|c|c|c|}
\hline Characteristic & Definition & $\begin{array}{l}\text { Osteosarcoma, } \\
\text { NOS }(N=222)\end{array}$ & $\begin{array}{l}\text { Chondroblastic } \\
\text { osteosarcoma }(N=66)\end{array}$ & $\begin{array}{l}\text { Fibroblastic } \\
\text { osteosarcoma }(N=14)\end{array}$ & Paget osteosarcoma $(N=11)$ & $P$ \\
\hline \multirow[t]{3}{*}{ Age } & $\leq 18$ & $45(20.3)$ & $15(22.7)$ & $2(14.3)$ & $0(0.0)$ & \multirow[t]{3}{*}{$<0.001$} \\
\hline & $19-50$ & $108(48.6)$ & $37(56.1)$ & $7(50.0)$ & $0(0.0)$ & \\
\hline & $50+$ & $69(31.1)$ & $14(21.2)$ & $5(35.7)$ & $11(100.0)$ & \\
\hline \multirow[t]{2}{*}{ Sex } & Female & $105(47.3)$ & $20(45.5)$ & $10(71.4)$ & $4(36.4)$ & \multirow[t]{2}{*}{0.28} \\
\hline & Male & $117(52.7)$ & $36(54.5)$ & $4(28.6)$ & $7(63.6)$ & \\
\hline \multirow[t]{3}{*}{ Surgery } & Yes & $187(84.2)$ & $59(89.4)$ & $11(78.6)$ & $7(63.6)$ & \multirow[t]{3}{*}{0.20} \\
\hline & No & $25(11.3)$ & $7(10.6)$ & $3(21.4)$ & $3(27.3)$ & \\
\hline & Unknown & $10(4.5)$ & $0(0.0)$ & $0(0.0)$ & $1(9.1)$ & \\
\hline \multirow[t]{3}{*}{ Radiotherapy } & No & $145(65.3)$ & $48(72.7)$ & $9(64.3)$ & $6(54.5)$ & \multirow[t]{3}{*}{0.62} \\
\hline & Yes & $71(32.0)$ & $15(22.7)$ & $5(35.7)$ & $5(45.5)$ & \\
\hline & Unknown & $6(2.7)$ & $3(4.5)$ & $0(0.0)$ & $0(0.0)$ & \\
\hline \multirow[t]{4}{*}{ Extent of disease } & Local & $57(25.7)$ & $21(31.8)$ & $4(28.6)$ & $2(18.2)$ & \multirow[t]{4}{*}{0.45} \\
\hline & Locoregional & $123(55.4)$ & $40(60.6)$ & $8(57.1)$ & $5(45.5)$ & \\
\hline & Metastasized & $13(5.9)$ & $1(1.5)$ & $0(0.0)$ & $1(9.1)$ & \\
\hline & Unknown & $29(13.1)$ & $4(6.1)$ & $2(14.3)$ & $3(27.3)$ & \\
\hline \multirow[t]{3}{*}{ Tumor size } & $\leq 50 \mathrm{~mm}$ & 97 (43.7) & $30(45.5)$ & $8(57.1)$ & $5(45.5)$ & \multirow[t]{3}{*}{0.61} \\
\hline & $>50 \mathrm{~mm}$ & $52(23.4)$ & $21(31.8)$ & $3(21.4)$ & $2(18.2)$ & \\
\hline & Unknown & 73 (32.9) & $15(22.7)$ & $3(21.4)$ & $4(36.4)$ & \\
\hline 5-Y survival* & $\%$ & 46.5 & 75.0 & 50.0 & 11.1 & 0.001 \\
\hline $10-Y$ survival** & $\%$ & 32.0 & 64.7 & 37.5 & 0.0 & $<0.001$ \\
\hline
\end{tabular}

*142 osteosarcoma, NOS, 44 chondroblastic osteosarcoma, 10 fibroblastic osteosarcoma, 9 Paget osteosarcoma

**128 osteosarcoma, NOS, 34 chondroblastic osteosarcoma, 8 fibroblastic osteosarcoma, 9 Paget osteosarcoma

$\mathrm{mm}$ millimeters, $N$ number of cases, $P p$ value, $Y$ year

recommend that radiotherapy should always be administered, since microscopic free margins are next to impossible [14]. Dural involvement is nevertheless a common phenomenon in these tumors [39]. A recent study found that radiotherapy reduces local recurrences in limb EWS, but this effect was less clear in axial EWS [1]. Also, when wide resection was achieved, local control was not ameliorated [1]. One study in 51 EWS of the head and neck, including 32 of the skull, indicated that less than radical excision significantly decreases event-free and overall survival [19].

Older age is significantly associated with worse survival in EWS generally [5, 38]. However, many older patients present with larger, more advanced masses, and also more commonly in the pelvis; these are all three negative predictors of survival as well $[5,38]$. In head and neck EWS, age over 15 has been reported to significantly reduce survival [19]. This was not found in this study, neither in univariate nor multivariate analyses. Also, in EWS tumors in other tumor sites, size over $150 \mathrm{cc}$ and elevated LDH levels have been associated with worse survival [5]. In skull EWS, this has not yet been demonstrated. A five-year overall survival varies from 39 to $100 \%$ $[14,19,30,39]$. With a 5 -year survival rate of $68.5 \%$, this study seems in line with previous findings. Survival is generally better compared to other sites of origin, which may partially be due to infrequent metastasis $[19,49]$. Overall, 20
$30 \%$ of extracranial EWS present with metastatic disease [5, 12]. Metastasis can occur in $75-80 \%$ of primary extracranial EWS within 2 years, most common sites are lungs and bones, but central nervous system involvement has been reported for $10-33 \%$ of cases $[32,33,44]$. Recurrence is relatively infrequent $[14,39]$. In case of recurrence, death will usually follow shortly after [39]. Given the complexity of treatment in OSC and EWS of the skull, a multidisciplinary approach involving neurosurgeons, radiotherapists, and medical oncologists specialized in sarcomas is needed in order to optimize outcomes.

\section{Strengths and limitations}

This study has several limitations, predominantly associated with the retrospective registry design. Many data of interest had a significant amount of missing values, such as tumor size, which had to be imputed using a validated algorithm. Unfortunately, the registry does not contain any information on recurrence and progression-free survival. Also, the mode and dosage of radiotherapy are not registered, nor is the indication of its use. This makes the interpretation of the exact impact radiotherapy has, adjacent to surgery, difficult and prone to confounding by indication. Since margin status is not registered in SEER, it may well be true that many patients receiving radiotherapy had positive margins which could 
explain the negative effect radiotherapy seems to have in OSC. Also, radiotherapy may have been used as salvage treatment. Furthermore, the use and regimen of chemotherapy could not be extracted either. However, since neoadjuvant chemotherapy has been common practice since the 1980s, we may assume that the larger part of these patients will have received systemic treatment. As treatment regimens have changed over the past decades, we have tried to compensate for these differences by modeling the year of diagnosis as well. As such, a significant difference in survival was seen in OSC during the pre-chemotherapy era, but was not observed in the EWS population, possibly due to the small amount of patients. Moreover, as the classification of sarcomas has changed over the last decades, there is a possibility that some of the included tumors would not be classified similarly nowadays. However, most of the tumors included in this study are treated after 1990. Lastly, the group of OSC NOS may possibly contain other histological subtypes than osteoblastic OSC. However, since other subtypes are registered separately and osteoblastic OSC are the most common subtype of OSC, we may assume that these are also the most prevalent as has previously been done [3]. Despite these limitations, the SEER database allows for investigation of rare tumor sites of OSC and EWS. To the best of our knowledge, this is the largest series described to date of both OSC and EWS arising from the skull. For the first time, it has been possible to stratify survival differences for four subtypes of skull OSC. These bone malignancies are not part of any neurosurgeon's daily practice and are not necessarily part of centralized healthcare. Nationwide data provide a means to inform neurosurgeons on generally used therapeutic regimens and survival of these tumors in order to optimally inform and treat their patients.

\section{Conclusion}

Both skull OSC and EWS generally benefit from surgery. Skull OSC has a significantly worse survival compared to EWS. Older age, tumor advancement, no surgical treatment, and the use of radiotherapy are independent predictors of poor survival in skull OSC. Chondroblastic OSC of the skull have a significantly better overall survival, while those arising in Paget's disease of the bone have a dismal prognosis.

\section{Compliance with ethical standards}

Conflict of interest The authors declare that they have no conflict of interest.

Ethical approval All procedures performed in studies involving human participants were in accordance with the ethical standards of the institutional and/or national research committee (name of institute/committee) and with the 1964 Helsinki declaration and its later amendments or comparable ethical standards. For this type of study formal consent is not required.

Informed consent This article does not contain any studies with human participants performed by any of the authors.

Open Access This article is distributed under the terms of the Creative Commons Attribution 4.0 International License (http:// creativecommons.org/licenses/by/4.0/), which permits unrestricted use, distribution, and reproduction in any medium, provided you give appropriate credit to the original author(s) and the source, provide a link to the Creative Commons license, and indicate if changes were made.

\section{References}

1. Albergo JI, Gaston CLL, Parry MC, Laitinen MK, Jeys LM, Tillman RM, Abudu AT, Grimer RJ (2018) Risk analysis factors for local recurrence in Ewing's sarcoma: when should adjuvant radiotherapy be administered? Bone Joint J 100-B(2):247-255

2. Alvarez-Berdecia A, Schut L, Bruce DA (1979) Localized primary intracranial Ewing's sarcoma of the orbital roof. Case report. J Neurosurg 50(6):811-813

3. Arshi A, Sharim J, Park DY, Park HY, Yazdanshenas H, Bernthal NM, Shamie AN (2017) Prognostic determinants and treatment outcomes analysis of osteosarcoma and Ewing sarcoma of the spine. Spine J 17(5):645-655

4. Ashkan K, Pollock J, D’Arrigo C, Kitchen ND (1998) Intracranial osteosarcomas: report of four cases and review of the literature. $\mathrm{J}$ Neuro-Oncol 40(1):87-96

5. Bacci G, Longhi A, Ferrari S, Mercuri M, Versari M, Bertoni F (2006) Prognostic factors in non-metastatic Ewing's sarcoma tumor of bone: an analysis of 579 patients treated at a single institution with adjuvant or neoadjuvant chemotherapy between 1972 and 1998. Acta Oncol 45(4):469-475

6. Barker JP, Monument MJ, Jones KB, Putnam AR, Randall RL (2015) Secondary osteosarcoma: is there a predilection for the chondroblastic subtype? Orthopedics 38(5):e359-e366

7. Bursac Z, Gauss CH, Williams DK, Hosmer DW (2008) Purposeful selection of variables in logistic regression. Source Code Biol Med $3(17)$

8. Caron AS, Hajdu SI, Strong EW (1971) Osteogenic sarcoma of the facial and cranial bones. A review of forty-three cases. Am J Surg 122(6):719-725

9. Chander B, Ralte AM, Dahiya S, Sharma MC, Mahapatra AK, Sharma AK, Mukhopadhyay S, Sarkar C (2003) Primary osteosarcoma of the skull. A report of 3 cases. J Neurosurg Sci 47(3):177181

10. Chennupati SK, Norris R, Dunham B, Kazahaya K (2008) Osteosarcoma of the skull base: case report and review of literature. Int J Pediatr Otorhinolaryngol 72(1):115-119

11. Chou E-K, Chang C-S, Chen PK-T, Chen Y-R, Yu JC-K, Jung S-M, Chang SC-N (2009) Long-term management of craniofacial osteosarcoma. J Craniofac Surg 20(2):406-409

12. Cotterill SJ, Ahrens S, Paulussen M, Jurgens HF, Voute PA, Gadner H, Craft AW (2000) Prognostic factors in Ewing's tumor of bone: analysis of 975 patients from the European Intergroup Cooperative Ewing's Sarcoma Study Group. J Clin Oncol 18(17):3108-3114

13. Davidson MJ (1991) Ewing's sarcoma of the temporal bone. A case report. Oral Surg Oral Med Oral Pathol 72(5):534-536

14. Desai KI, Nadkarni TD, Goel A, Muzumdar DP, Naresh KN, Nair CN (2000) Primary Ewing's sarcoma of the cranium. Neurosurgery 46(1):62-69 
15. Durfee RA, Mohammed M, Luu HH (2016) Review of osteosarcoma and current management. Rheumatol Ther 3(2):221-243

16. Fitzer PM, Steffey WR (1976) Brain and bone scans in primary Ewing's sarcoma of the petrous bone. J Neurosurg 44(5):608-612

17. Gadwal SR, Gannon FH, Fanburg-Smith JC, Becoskie EM, Thompson LD (2001) Primary osteosarcoma of the head and neck in pediatric patients: a clinicopathologic study of 22 cases with a review of the literature. Cancer 91(3):598-605

18. Garland L (1945) Osteogenic sarcoma of the skull. Radiology 45: 45-48

19. Grevener K, Haveman LM, Ranft A, van den Berg H, Jung S, Ladenstein R, Klco-Brosius S, Juergens H, Merks JHM, Dirksen U (2016) Management and outcome of Ewing sarcoma of the head and neck. Pediatr Blood Cancer 63(4):604-610

20. Grier HE (1997) The Ewing family of tumors. Ewing's sarcoma and primitive neuroectodermal tumors. Pediatr Clin N Am 44(4):9911004

21. Guadagnolo BA, Zagars GK, Raymond AK, Benjamin RS, Sturgis EM (2009) Osteosarcoma of the jaw/craniofacial region: outcomes after multimodality treatment. Cancer 115(14):3262-3270

22. Guo Z, Hu K, Zhao B, Bian E, Ni S, Wan J (2017) Osteosarcoma of the skull base: an analysis of 19 cases and literature review. J Clin Neurosci 44:133-142

23. Hadley C, Gressot LV, Patel AJ, Wang LL, Flores RJ, Whitehead WE, Luerssen TG, Jea A, Bollo RJ (2014) Osteosarcoma of the cranial vault and skull base in pediatric patients. J Neurosurg Pediatr 13(4):380-387

24. Hansen MF, Nellissery MJ, Bhatia P (1999) Common mechanisms of osteosarcoma and Paget's disease. J Bone Miner Res 14(Suppl 2):39-44

25. Hansen MF, Seton M, Merchant A (2006) Osteosarcoma in Paget's disease of bone. J Bone Miner Res 21(Suppl 2):P58-P63

26. Haque F, Fazal ST, Ahmad SA, Abbas SZ, Naseem S (2006) Primary osteosarcoma of the skull. Australas Radiol 50(1):63-65

27. Hogendoorn PCW, Athanasou N, Bielack S et al (2010) Bone sarcomas: ESMO clinical practice guidelines for diagnosis, treatment and follow-up. Ann Oncol 21(Suppl 5):v204-v213

28. Huvos AG, Sundaresan N, Bretsky SS, Butler A (1985) Osteogenic sarcoma of the skull. A clinicopathologic study of 19 patients. Cancer 56(5):1214-1221

29. Kirby EJ, Zhou HH, Morales LJ (2011) Primary pediatric osteosarcoma of the skull. J Craniofac Surg 22(6):2399-2405

30. Krishnamani K, Kumar TN, Gandhi LV, Raghunadharao D, Sadashivudu G, Megha U (2014) Primary Ewing's sarcoma of the cranium: case series and review of literature. J Cancer Res Ther 10(2):377-380

31. Kundu ZS (2014) Classification, imaging, biopsy and staging of osteosarcoma. Indian J Orthop 48(3):238-246

32. Mansfield JB (1982) Primary Ewing's sarcoma of the skull. Surg Neurol 18(4):286-288

33. Mehta Y, Hendrickson FR (1974) CNS involvement in Ewing's sarcoma. Cancer 33(3):859-862
34. Mohanty S, Bilimoria KY (2014) Comparing national cancer registries: The National Cancer Data Base (NCDB) and the Surveillance, Epidemiology, and End Results (SEER) program. J Surg Oncol 109(7):629-630

35. Mukherjee D, Chaichana KL, Adogwa O, Gokaslan Z, Aaronson O, Cheng JS, McGirt MJ (2011) Association of extent of local tumor invasion and survival in patients with malignant primary osseous spinal neoplasms from the surveillance, epidemiology, and end results (SEER) database. World Neurosurg 76(6):580-585

36. Oda D, Bavisotto LM, Schmidt RA, McNutt M, Bruckner JD, Conrad EU 3rd, Weymuller EAJ (1997) Head and neck osteosarcoma at the University of Washington. Head Neck 19(6):513-523

37. Reed DR, Hayashi M, Wagner L et al (2017) Treatment pathway of bone sarcoma in children, adolescents, and young adults. Cancer 123(12):2206-2218

38. Rodriguez-Galindo C, Navid F, Liu T, Billups CA, Rao BN, Krasin MJ (2008) Prognostic factors for local and distant control in Ewing sarcoma family of tumors. Ann Oncol 19(4):814-820

39. Salunke PS, Gupta K, Malik V, Kumar N, Henke LE, Cai C, Chen W-S, Pfeifer JD (2011) Primary Ewing's sarcoma of cranial bones: analysis of ten patients. Acta Neurochir 153(7):1477-1485

40. Salvati M, Ciappetta P, Raco A (1993) Osteosarcomas of the skull. Clinical remarks on 19 cases. Cancer 71(7):2210-2216

41. Schwarz R, Bruland O, Cassoni A, Schomberg P, Bielack S (2009) The role of radiotherapy in oseosarcoma. Cancer Treat Res 152: $147-164$

42. Shinoda J, Kimura T, Funakoshi T, Iwata H, Tange K, Kasai C, Miyata Y (1993) Primary osteosarcoma of the skull. J NeuroOncol 17(1):81-88

43. Smeele LE, Kostense PJ, van der Waal I, Snow GB (1997) Effect of chemotherapy on survival of craniofacial osteosarcoma: a systematic review of 201 patients. J Clin Oncol 15(1):363-367

44. Steinbok P, Flodmark O, Norman MG, Chan KW, Fryer CJ (1986) Primary Ewing's sarcoma of the base of the skull. Neurosurgery 19(1):104-107

45. Sundaresan N, Rosen G, Boriani S (2009) Primary malignant tumors of the spine. Orthop Clin North Am 40(1):21-36, v

46. Ta HT, Dass CR, Choong PFM, Dunstan DE (2009) Osteosarcoma treatment: state of the art. Cancer Metastasis Rev 28(1-2):247-263

47. Buuren van S, Groothuis-Oudshoorn K (2011) Mice: multivariate imputation by chained equations in R. J. Stat Software 1(3)

48. Waljee AK, Mukherjee A, Singal AG, Zhang Y, Warren J, Balis U, Marrero J, Zhu J, Higgins PD (2013) Comparison of imputation methods for missing laboratory data in medicine. BMJ Open. https://doi.org/10.1136/bmjopen-2013-002847

49. Watanabe H, Tsubokawa T, Katayama Y, Koyama S, Nakamura S (1992) Primary Ewing's sarcoma of the temporal bone. Surg Neurol 37(1):54-58

50. Wu G, Liang Q, Liu Y (2017) Primary osteosarcoma of frontal bone: a case report and review of literature. Medicine (Baltimore) 96(51):e9392 